\title{
Elizabeth Vinestock, Poétique et pratique dans les «Poemes» de Jean-Antoine de Baïf
}

\section{Dario Cecchetti}

\section{Q OpenEdition}

1 Journals

\section{Edizione digitale}

URL: https://journals.openedition.org/studifrancesi/26098

DOI: 10.4000/studifrancesi.26098

ISSN: 2421-5856

\section{Editore}

Rosenberg \& Sellier

\section{Edizione cartacea}

Data di pubblicazione: 1 avril 2007

Paginazione: 161

ISSN: 0039-2944

\section{Notizia bibliografica digitale}

Dario Cecchetti, «Elizabeth Vinestock, Poétique et pratique dans les «Poemes» de Jean-Antoine de Baif»», Studi Francesi [Online], 151 (LI | I) | 2007, online dal 30 novembre 2015, consultato il 23 novembre 2021. URL: http://journals.openedition.org/studifrancesi/26098; DOI: https://doi.org/10.4000/ studifrancesi.26098

Questo documento è stato generato automaticamente il 23 novembre 2021.

\section{(c) $(1) \odot$}

Studi Francesi è distribuita con Licenza Creative Commons Attribuzione - Non commerciale - Non opere derivate 4.0 Internazionale. 


\title{
Elizabeth Vinestock, Poétique et pratique dans les «Poemes» de Jean- Antoine de Baïf
}

\author{
Dario Cecchetti
}

\section{NOTIZIA}

ELIZABETH VINeSTock, Poétique et pratique dans les «Poemes» de Jean-Antoine de Baïf, Paris, Champion («Études et essais sur la Renaissance», LXXI), 2006, pp. 271.

Mentre è in corso presso Champion, sotto la direzione di Jean Vignes, l'edizione critica delle CEuvres complètes di Jean-Antoine de Baïf (del 2002 è l'eccellente edizione dei Neuf livres des Poemes: cfr. questi «Studi», 143, 2004, pp. 348-349), E. Vinestock - proprio a partire da una lettura d'insieme dei Poemes, che ne mette in luce la varietà di genere, di metro, di argomento e di stile - intende ricostruire, in assenza di un art poétique vero e proprio, la poetica del grande contemporaneo di Ronsard, quale si evince dalle tematiche trattate, soprattutto da quella, dominante, del valore del poeta e della poesia. Come sottolinea l'A., in questa perlustrazione dei Poemes ci si occupa degli elementi strutturali, della riflessività del testo, dell'intertestualità e, in particolare modo, di quella retorica al centro dell'attenzione degli autori cinquecenteschi, che viene nuovamente considerata di primaria importanza dagli odierni studi di letteratura. «Il centro di interesse è anzitutto l'identità della raccolta, la sua posizione all'interno delle Euvres en rime di Baïf, la natura del suo contenuto, la sua struttura e i suoi temi. Due problemi teorici considerati fin dall'inizio concernono lo statuto generico del poeme e la definizione del termine, giacché Baif l'applica a numerosi tipi di composizione di forma e lunghezza diversa, di argomenti, di stili e di toni svariati. In secondo luogo si esamina la costituzione della raccolta per tentare di scoprirvi i principi strutturali soggiacenti. Malgrado l'assenza di una struttura netta e rigorosa, vengono individuati alcuni fattori che conferiscono una certa coerenza alla raccolta» (p. 13). Questi fattori consistono nella ricorrenza di certi temi o nel modo di affrontare alcune problematiche essenziali 
della poetica - o meglio delle poetiche - del Rinascimento. Così, nel secondo capitolo (L'art poétique de Baïf, pp. 63-106) si insiste sul già citato motivo del valore della poesia $\mathrm{e}$ del poeta; come pure, nel terzo capitolo (Traduction, adaptation imitation, pp. 107-149), sfruttando il fatto che l'edizione diretta da Jean Vignes ha repertoriato fonti e archetipi, si procede a un'indagine particolareggiata circa le diverse procedure adottate nell'imitazione o nella trasformazione dei modelli. Interessanti, infine, sono il quarto e quinto capitolo consacrati allo studio dell'applicazione delle tecniche della retorica classica, dell'inventio e della dispositio (pp. 151-181) e dell'elocutio (pp. 183-213), ove si illustra in particolare come i metodi della retorica tradizionale aiutino Baif ad adempiere alle funzioni poetiche del movere del delectare, del docere. L'ultimo capitolo (Versification, pp. 215-235) analizza le riuscite metriche, dimostrando come Baïf «maneggi con sapienza forme differenti e sfrutti tutte le risorse della metrica, del ritmo, della rima e della fonologia. per creare uno strumento flessibile e originale» (p. 215). Si conclude così la sintesi di E. Vinestock, utile per chi studia la poetica del Cinquecento francese e rivalutativa e chiarificatrice circa l'opera di Baïf. 